\title{
Cardiomiopatia Dilatada: Nova Variante no Gene da Filamina-C
}

\section{Dilated Cardiomyopathy: New Variant in the Filamin-C Gene}

\author{
Murilo Zomer Frasson ${ }^{1}{ }^{(10}$ e Cristiano Pederneiras Jaeger ${ }^{1}$ (1) \\ Hospital Mãe de Deus - Residência Médica de Cardiologia, ${ }^{1}$ Porto Alegre, RS - Brasil
}

\section{Relato de Caso}

Apresentamos o relato de caso de um paciente masculino de 50 anos de idade que procurou o departamento de pronto-socorro de nossa instituição com queixa de dispneia progressiva há 1 semana. O paciente relatava história prévia de fibromialgia e negava demais comorbidades, como infarto miocárdico ou acidente vascular cerebral. Negava tabagismo atual e fazia uso eventual de álcool. Como medicamentos de uso contínuo, utilizava duloxetina, pregabalina e zolpidem. Mãe e primos com história de insuficiência cardíaca por miocardiopatia dilatada idiopática, sem demais comorbidades cardiovasculares em seu histórico familiar.

Ao exame físico, apresentava sinais vitais estáveis, crepitações em bases pulmonares e edema de membros inferiores. Ausculta cardíaca sem comemorativos. Eletrocardiograma realizado mostrava ritmo sinusal, sem sinais de sobrecarga atrial ou ventricular (Figura 1). Radiografia de tórax revelou cardiomegalia. Nos exames laboratoriais, chamava a atenção um NT-pró-BNP de $2.335 \mathrm{pg} / \mathrm{mL}$, e a série de troponinas T ultrassensíveis revelou valores consecutivos de $0,074 \mathrm{ng} / \mathrm{mL}$ e $0,072 \mathrm{ng} / \mathrm{mL}$ (valor de referência $<0,014 \mathrm{ng} / \mathrm{mL}$ ).

O paciente foi internado para investigação. Ecocardiograma revelou uma cardiopatia dilatada com fração de ejeção de $37,1 \%$, com uma hipocinesia difusa das paredes do ventrículo esquerdo. Um cateterismo cardíaco revelou coronárias sem estenoses significativas. Foi realizada ressonância magnética cardíaca, que demonstrou fração de ejeção de $27 \%$ com disfunção sistólica global e ausência de fibrose, sugerindo cardiomiopatia dilatada idiopática. Também foi realizado holter de 24 horas, que não evidenciou arritmias ventriculares durante o período de monitoramento.

Após compensação com medidas para insuficiência cardíaca na instituição, o paciente realizou teste genético para cardiomiopatias hereditárias, tendo sido analisados os genes listados na Tabela 1. A análise foi feita com extração e fragmentação do DNA genômico, seguida de identificação, captura e enriquecimento das regióes de interesse. O resultado de tal exame revelou uma variante provavelmente patogênica

\section{Palavras-chave}

Doenças Cardiovasculares/fisiopatologia; Cardiomiopatia Dilatada/genética; Insuficiência Cardíaca; Filaminas.

Correspondência: Murilo Zomer Frasson •

Hospital Mãe de Deus - Residência Médica de Cardiologia - Rua José de Alencar, 286. CEP 90880-480, Porto Alegre, RS - Brasil

E-mail: frasson.murilo@gmail.com

Artigo recebido em 13/03/2020, revisado em 31/08/2020, aceito em $04 / 11 / 2020$

DOI: https://doi.org/10.36660/abc.20200199
c.1595delIT em heterozigose no gene da filamina-C (FLNC). Este gene tem sido associado a uma série de cardiopatias, tais como: (1) cardiomiopatia hipertrófica familiar, de herança não determinada; (2) cardiomiopatia restritiva familiar, ${ }^{1}$ de herança autossômica dominante [OMIM: 617047]; (3) miopatia distal de herança autossômica dominante [OMIM: 614065]; e (4) miopatia miofibrilar, de herança autossômica dominante [OMIM: 609524]. ${ }^{2}$ A variante identificada é caracterizada pela deleção de um nucleotídio que, preditamente, leva à alteração da matriz de leitura (frameshift) ao promover a substituição do aminoácido valina no códon 532 por uma glicina, com consequente parada precoce da tradução proteica 16 posições à frente (p.(Val532Glyfs*16)) resultando em uma proteína truncada. A variante está ausente nos bancos de frequência populacionais (Exome Aggregation Consortium [ExAC] e The Genome Aggregation Database [GnomAD]), ${ }^{3}$ não foi descrita na literatura médica em nenhum momento e nunca foi observada no banco de dados ClinVar. ${ }^{4} \mathrm{~A}$ filamina-C é uma proteína expressada principalmente no músculo cardíaco e músculo esquelético, sendo codificada pelo gene FLNC. A proteína é responsável pelo crosslink dos filamentos de actina em redes ortogonais no citoplasma cortical das células e participa da ancoragem de proteínas de membrana para o citoesqueleto da actina. ${ }^{5}$ Devido a essas funções e sua expressão no músculo cardíaco predominante, o gene FLNC tem sido relacionado a cardiomiopatias dilatadas ou arritmogênicas. ${ }^{6}$ Segundo as métricas disponíveis no banco de dados GnomAD, o gene FLNC não tolera alterações loss-of-function. Ademais, mutações frameshift têm sido relacionadas às doenças de cardiomiopatia arritmogênica/ dilatada. ${ }^{7}$ De acordo com os critérios do American College of Medical Genetics and Genomics (ACMG), ${ }^{8}$ esta variante encontrada é classificada como provavelmente patogênica.

O paciente apresentou melhora clínica com o tratamento, tendo recebido alta com furosemida, sacubitril-valsartana e carvedilol. Foi recomendado aconselhamento genético à família, posto que familiares em primeiro grau de indivíduos portadores de variantes patogênicas em heterozigose do gene FLNC têm 50\% de probabilidade de serem portadores da mesma variante. Apesar do risco de arritmias ventriculares importantes, neste caso específico, o paciente optou pelo não implante de cardiodesfibrilador (CDI) em um primeiro momento. Quanto a esse aspecto de prevenção de morte súbita cardíaca, lembramos que o estudo DANISH ${ }^{9}$ não demonstrou benefício em termos de diminuição de mortalidade em pacientes com insuficiência cardíaca de fração de ejeção reduzida de etiologia não isquêmica. Contudo, é importante ressaltar que, de acordo com diretrizes da Sociedade Brasileira de Cardiologia, pacientes com insuficiência cardíaca de etiologia não isquêmica com fração de ejeção $\leq 35 \%$ poderão ter indicação de CDI, inclusive para profilaxia primária (Classe 


\section{Relato de Caso}

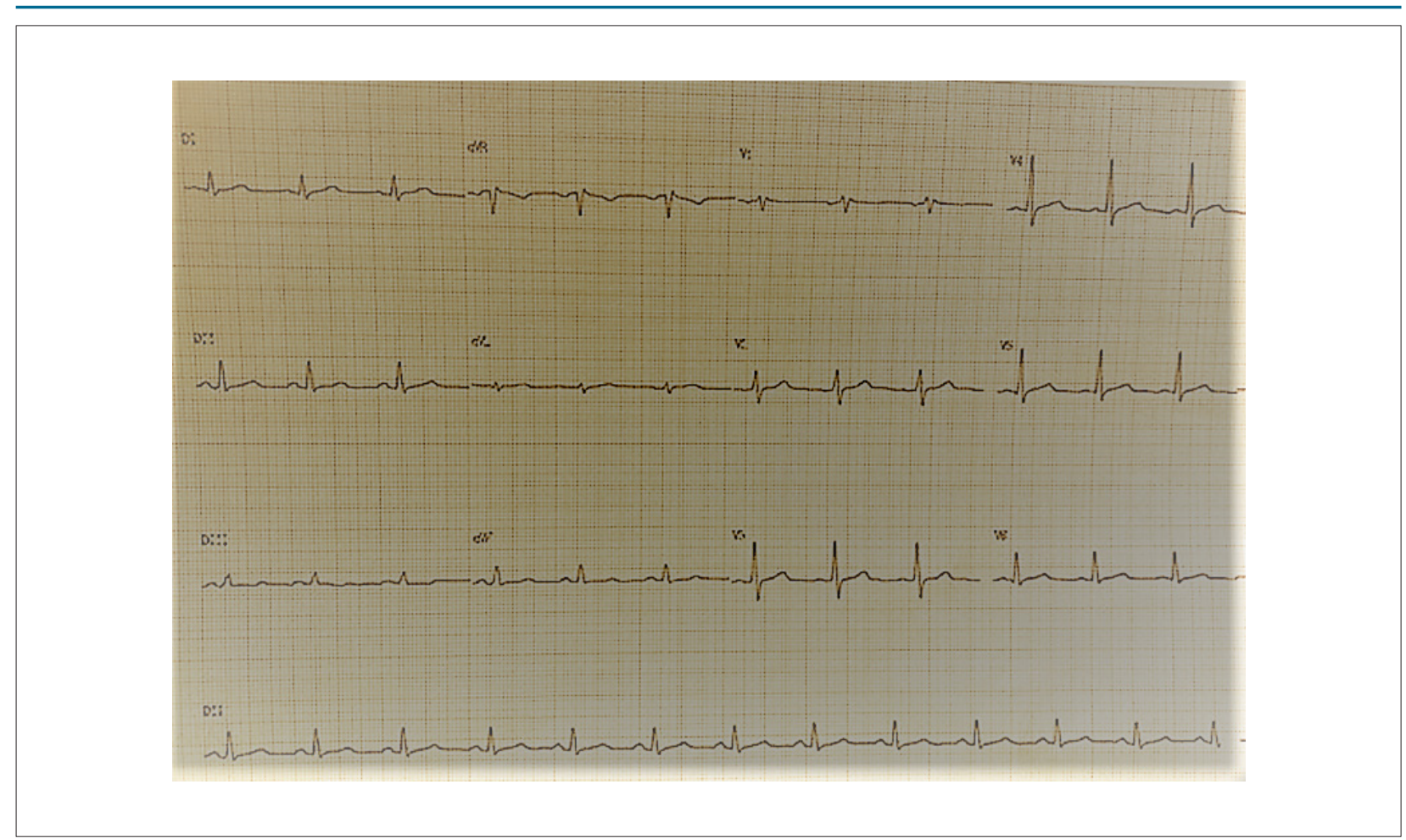

Figura 1 - Eletrocardiograma.

\section{Tabela 1 - Painel genético analisado}

ABCC9; ACTC1; ACTN2; ANK2; BAG3; BRAF; CALR3; CAV3; CBL; CRYAB; CSRP3; DES; DSC2; DSG2; DSP; DTNA; EMD; EYA4; FHL1; FKTN; FLNC; GAA; GLA; HRAS; JPH2; JUP; KRAS; LAMP2; LDB3; LMNA; MAP2K1; MAP2K2; MYBPC3; MYH6; MYH7; MYL2; MYL3; MYLK2; MYOT; MYOZ2; NEBL; NEXN; NRAS; PKP2; PLN; PRKAG2; PSEN1; PSEN2; PTPN11; RAF1; RBM20; RPSA; RYR2; SCN5A; SGCD; SHOC2; SLC25A4; SOS1; SPRED1; SYNE1; SYNE2; TAZ; TCAP; TGFB3; TMEM43; TMPO; TNNC1; TNNI3; TNNT2; TPM1; TRIM63; TTN; TTR; VCL.

Ila). ${ }^{10}$ Além disso, as diretrizes do Heart Rhythm Journal de $2019^{11}$ citam que, em pacientes com cardiomiopatia arritmogênica ligada a mutação no gene FLNC e fração de ejeção $<45 \%$, o implante do CDI é terapia a ser considerada (Classe Ila/C). Esta seria uma recomendação mais específica, visto que leva em consideração o caráter genético da patologia do paciente. Sentimos que a decisão quanto ao implante ou não de CDI deva levar em conta as evidências literárias, mas que também seja individualizada, observando-se sempre a vontade do paciente e sua qualidade e expectativa de vida.

Diante de tal relato, consideramos a importância de se buscar ativamente a etiologia para casos de insuficiência cardíaca presumidamente idiopática, incluindo a pesquisa genética, visto que há a possibilidade de que seja encontrado um fator causal para a doença de um paciente, que muitas vezes pode estar sendo privado de um diagnóstico mais específico. Evidentemente, existem certas dificuldades para a oferta do rastreamento genético, tais como baixa disponibilidade do exame em muitos locais, preço elevado e falta de difusão do conhecimento genético entre os cardiologistas gerais. Salienta-se que a genética é um campo ainda em grande desenvolvimento, no qual certamente muitas mutações e variantes patogênicas ainda devem ser catalogadas, possibilitando orientações muito mais precisas ao paciente e seus familiares, uma vez determinada a origem da patologia em questão.

\section{Contribuição dos autores}

Concepção e desenho da pesquisa, Obtenção de dados, Análise e interpretação dos dados, Redação do manuscrito e Revisão crítica do manuscrito quanto ao conteúdo intelectual importante: Frasson MZ e Jaeger CP.

\section{Potencial conflito de interesse}

Não há conflito com o presente artigo

\section{Fontes de financiamento}

O presente estudo não teve fontes de financiamento externas. 


\section{Vinculação acadêmica}

Não há vinculação deste estudo a programas de pós-graduação.

\section{Referências}

1. Brodehl A, Ferrier RA, Hamilton SJ, Greenway SC, Brundler MA, Yu W, et al. Mutations in FLNC are associated with familial restrictive cardiomyopathy. Human Mutation. 2016; 37(3):269-79. doi:10.1002/humu.22942

2. OMIN Online Mendelian Inheritance in man: an online catalog of human genes and genetic disorders: update June 23, 2021. [Internet] [Cited in 2021 June ] Available from:omnium.org.

3. The Genome Aggregation Database (gnomAD). [Internet] [Cited in 2021 June 21] Available from: https://gnomad.broadinstitute.org/.

4. ClinVar. Clin Var aggregates information about genomic variation and its relationship to human health. [Internet]. [Cited in 2021 June 23]. Available from: ncbi.nlm.nih/clinvar/

5. Maestrini E, Patrosso C, Mancini M, Rocchi m, Repetto M, Villa A, et al.Mapping of two genes encoding isoforms of the actin binding protein ABP-280, a dystrophin like protein, to Xq28 and to chromosome 7. Hum Molec Genet.1993;2(6):761-6. doi:10.1093/hmg/2.6.761.

6. Ortiz-Genga MF, Cuenca S, Dal Ferro M, Zorio E, Salgado-Aranda R, Climent $\mathrm{V}$, et al. Truncating FLNC mutations are associated with high-risk dilated and arrhythmogenic cardiomyopathies. J Am Coll Cardiol. 2016; 68(22):2440 51. doi:10.1016/j.jacc.2016.09.927.

\section{Aprovação ética e consentimento informado}

Este artigo não contém estudos com humanos ou animais realizados por nenhum dos autores.

7. Bienengraeber M, Olson TM, Selivanov VA, Kathmann EC, O'Cochlain F, Gao F, et al. ABCC9 mutations identified in human dilated cardiomyopathy disrupt catalytic KATP channel gating. Nat Genet. $2004 ; 36: 382-7$.

8. Richards S, Aziz N, Bale S, Beck D, Das S, Gastier-Foster J, et al Standards and guidelines for the interpretation of sequence variants: a joint consensus recommendation of the American College of Medical Genetics and Genomics and the Association for Molecular Pathology. Genet Med. 2015; 17(5):405-24 doi:10.1038/gim.2015.30.

9. Køber L, Thune JJ, Nielsen JC, Haarbo J, Videbaek L, Korup E, et al. Defibrillator implantation in patients with nonischemic systolic heart failure. N Engl J Med. 2016; 375(13):1221-30

10. Sociedade Brasileira de Cardiologia. Diretriz de Insuficiência Cardíaca Diretriz de Insuficiência Cardíaca Crônica e Aguda. Arq Bras Cardiol. 2018; 111:436-539.

11. Towbin JA, McKenna WJ, Abrams DJ. HRS expert consensus statement on evaluation, risk stratification, and management of arrhythmogenic cardiomyopathy: executive summary. Heart Rhythm. 2019; 16(11):e373-e407. doi:10.1016/j.h 